\title{
ANOTHER GENERALIZED FIBONACCI SEQUENCE
}

\author{
MARCELLUS E. WADDILL AND LOUIS SACKS \\ Wake Forest College, Winston Salem, N.C., and University of Pittsburgh, Pittsburgh, Pa.
}

\section{INTRODUCTION}

Recent issues of numerous periodicals have given indication of a renewed interest in the well-known Fibonacci sequence, namely

$$
1,1,2,3,5,8, \cdots, \mathrm{C}_{\mathrm{n}}, \cdots,
$$

where

$$
\mathrm{C}_{\mathrm{n}}=\mathrm{C}_{\mathrm{n}-1}+\mathrm{C}_{\mathrm{n}-2}, \mathrm{n} \geq 3 \text {, with } \mathrm{C}_{1}=\mathrm{C}_{2} \stackrel{\stackrel{1}{=}}{1} \text {. }
$$

Some recent generalizations have produced a variety of new and extended results. .

A search of the literature seems to reveal that efforts to generalize the Fibonacci sequence have consisted of either (a) changing the recurrence relation while preserving the initial terms, or (b) altering the initial terms but maintaining the recurrence relation. A combination of these two techniques will be employed here.

Heretofore, all generalizations of the Fibonacci sequence appear to have restricted any given term to being a function (usually sum) of the two preceding terms. In this paper we shall extend this by considering sequences in which any given term is the sum of the three preceding it.

Since the set of all algebraic integers, i.e., all $y$ such that $y$ satisfies some monic polynomial equation,

$$
p(x) \equiv x^{n}+a_{n-1} x^{n-1}+\cdots+a_{1} x+a_{0}=0,
$$

with integral coefficients and of degree greater than zero, is an integral domain under the operations of addition and multiplication, it was considered worthwhile to examine sequences in which the initial terms (hence all succeeding terms) are algebraic integers. It will be shown that certain special cases of such sequences are especially useful in the examination of the more general case. 


\section{THE GENERALIZED SEQUENCE $\left\{P_{n}\right\}$}

Specifically we consider the sequence

$$
\left\{P_{n}\right\} \equiv P_{0}, P_{1}, P_{2}, \cdots, P_{n}, \cdots,
$$

where $P_{0}, P_{1}, P_{2}$ are given, arbitrary algebraic integers, not all zero, and

$$
P_{n}=P_{n-1}+P_{n-2}+P_{n-3}, \quad n \geq 3 \text {. }
$$

It will also be convenient to consider a companion sequence, so to speak,

(4)

$$
\left\{R_{n}\right\} \equiv R_{0}, R_{1}, R_{2}, \cdots, R_{n}, \cdots,
$$

where

$$
R_{0}=P_{1}-P_{0}, \quad R_{1}=P_{2}-P_{1}, \quad \text { and for } n \geq 2 \text {, }
$$

(5)

$$
R_{n}=P_{n-1}+P_{n-2}
$$

From (5) and (3), when $n \geq 5$, we have

$$
\begin{aligned}
R_{n}=P_{n-1}+P_{n-2} & =\left(P_{n-2}+P_{n-3}\right)+\left(P_{n-4}+P_{n-3}\right)+\left(P_{n-4}+P_{n-5}\right) \\
& =R_{n-1}+R_{n-2}+R_{n-3} .
\end{aligned}
$$

Using (5) and (3) further, we have

$$
\begin{aligned}
& \mathrm{R}_{4}=\mathrm{R}_{3}+\mathrm{R}_{2}+\mathrm{R}_{1}, \\
& \mathrm{R}_{3}=\mathrm{R}_{2}+\mathrm{R}_{1}+\mathrm{R}_{0} .
\end{aligned}
$$

Hence for $\mathrm{n} \geq 3$,

(6)

$$
R_{n}=R_{n-1}+R_{n-2}+R_{n-3}^{i}
$$


Thus $\left\{R_{n}\right\}$ is actually the special case of (2) in which $R_{0}=P_{1}-P_{0}$, $R_{1}=P_{2}-P_{1}, \quad R_{2}=P_{1}+P_{0}$ 。 The usefulness of the sequence $\left\{R_{n}\right\}$ will be evident in the development of $\left\{P_{n}\right\}$ that follows.

Two other special cases of (2) should be mentioned at this time; namely the cases in which $P_{0}=0, P_{1}=P_{2}=1$ and $P_{0}=1, P_{1}=0, P_{2}=1$ respectively, to give the sequences

$$
0,1,1,2,4,7,13,24,44, \cdots, \mathrm{K}_{\mathrm{n}}, \cdots,
$$

and

$$
1,0,1,2,3,6,11,20,37, \cdots, \mathrm{L}_{\mathrm{n}}, \cdots \cdot
$$

We see immediately that $L_{0}=K_{1}-K_{0}, L_{1}=K_{2}-K_{1}$, and for $n \geq 2$,

$$
\mathrm{L}_{\mathrm{n}}=\mathrm{K}_{\mathrm{n}-1}+\mathrm{K}_{\mathrm{n}-2} \text {. }
$$

Hence we might call $\left\{\mathrm{K}_{\mathrm{n}}\right\}$ a $\mathrm{P}_{\mathrm{n}}$-type sequence and $\left\{\mathrm{L}_{\mathrm{n}}\right\}$ an $\mathrm{R}_{\mathrm{n}}$-type sequence.

The sequence $\left\{\mathrm{K}_{\mathrm{n}}\right\}$ was defined and discussed brieflyby M. Agronomoff [1]. The following three relations involving various terms of this sequence were discovered and proved by him:

$$
\begin{gathered}
K_{n+p}=K_{p+1} K_{n}+\left(K_{p-1}+K_{p}\right) K_{n-1}+K_{p} K_{n-2}, \\
K_{2 n}=K_{n-1}^{2}+K_{n}\left(K_{n+1}+K_{n-1}+K_{n-2}\right), \\
K_{2 n-1}=K_{n}^{2}+K_{n-1}^{2}+2 K_{n-1} K_{n-2} .
\end{gathered}
$$

There is only one basic identity here because the latter two are evidently special cases of the first one upon setting $p=n$ and $p=n-1$ respectively.

Further, it was conjectured in [1] that even though the sequence (7) was a Fibonacci-type sequence, it quite possibly would possess few of the interesting properties which the Fibonacci sequence has, and even if it should, such properties would be much more difficult to find dueto the more complex nature of the recurrence relation determining the sequence. 
We turn now to an investigation of the sequence (2) and consider, among other facts, how (10), (11), and (12) occur as special cases of more general relations.

Paralleling the usual treatment of the Fibonacci sequence, we obtain a closed expression for $P_{n}$ since $\left\{P_{n}\right\}$ satisfies a difference equation. Thus

$$
P_{n}=B_{1} x_{1}^{n}+B_{2} x_{2}^{n}+B_{3} x_{3}^{n}
$$

where $x_{1}, x_{2}, x_{3}$ are the three distinct roots of the equation

$$
x^{3}-x^{2}-x-1=0
$$

and $B_{1}, B_{2}, B_{3}$ are constants depending on these roots as well as $P_{0}, P_{1}$, $\mathrm{P}_{2}$, and are determined by the system

$$
\left\{\begin{array}{l}
\mathrm{B}_{1}+\mathrm{B}_{2}+\mathrm{B}_{3}=\mathrm{P}_{0} \\
\mathrm{~B}_{1} \mathrm{x}_{1}+\mathrm{B}_{2} \mathrm{x}_{2}+\mathrm{B}_{3} \mathrm{x}_{3}=\mathrm{P}_{1} \\
\mathrm{~B}_{1} \mathrm{x}_{1}^{2}+\mathrm{B}_{2} \mathrm{x}_{2}^{2}+\mathrm{B}_{3} \mathrm{x}_{3}^{2}=\mathrm{P}_{2}
\end{array}\right.
$$

The values of $x_{1}, x_{2}, x_{3}, B_{1}, B_{2}, B_{3}$ are such as to make (12) too cumbersome to be of any further practical use in the succeeding development and hence will not be written here.

A much more useful way of representing the recurrence relation for $\left\{P_{n}\right\}$ may be found as follows: In the notation of vectors and matrices, we have by (3),

$$
\begin{gathered}
{\left[\begin{array}{l}
P_{3} \\
P_{2} \\
P_{1}
\end{array}\right]=\left[\begin{array}{lll}
1 & 1 & 1 \\
1 & 0 & 0 \\
0 & 1 & 0
\end{array}\right]\left[\begin{array}{l}
P_{2} \\
P_{1} \\
P_{0}
\end{array}\right],} \\
{\left[\begin{array}{l}
P_{4} \\
P_{3} \\
P_{2}
\end{array}\right]=\left[\begin{array}{lll}
1 & 1 & 1 \\
1 & 0 & 0 \\
0 & 1 & 0
\end{array}\right]\left[\begin{array}{l}
P_{3} \\
P_{2} \\
P_{1}
\end{array}\right]=\left[\begin{array}{lll}
1 & 1 \\
1 & 0 & 0 \\
0 & 1 & 0
\end{array}\right]\left[\begin{array}{l}
P_{2} \\
P_{1} \\
P_{0}
\end{array}\right],}
\end{gathered}
$$


and by finite induction

$$
\left[\begin{array}{l}
P_{n} \\
P_{n-1} \\
P_{n-2}
\end{array}\right]=\left[\begin{array}{lll}
1 & 1 & 1 \\
1 & 0 & 0 \\
0 & 1 & 0
\end{array}\right]^{n-2}\left[\begin{array}{c}
P_{2} \\
P_{1} \\
P_{0}
\end{array}\right]
$$

Further, a simple induction proof gives

$$
\left[\begin{array}{lll}
1 & 1 & 1 \\
1 & 0 & 0 \\
0 & 1 & 0
\end{array}\right]^{n}=\left[\begin{array}{ccc}
K_{n+1} & L_{n+1} & K_{n} \\
K_{n} & L_{n} & K_{n-1} \\
K_{n-1} & L_{n-1} & K_{n-2}
\end{array}\right]
$$

so it might be said that $\left\{\mathrm{K}_{n}\right\}$ and $\left\{\mathrm{L}_{\mathrm{n}}\right\}$ arise "naturally" in the investigation of $\left\{\mathrm{P}_{\mathrm{n}}\right\}$.

Using (14) and (15), we find for $n, p$ positive integers that

$$
\left[\begin{array}{c}
P_{n+p} \\
P_{n+p-1} \\
P_{n+p-2}
\end{array}\right]=\left[\begin{array}{ccc}
K_{p+1} & L_{p+1} K_{p} \\
K_{p} & L_{p} & K_{p-1} \\
K_{p-1} & L_{p-1} & K_{p-2}
\end{array}\right]\left[\begin{array}{c}
P_{n} \\
P_{n-1} \\
P_{n-2}
\end{array}\right],
$$

from which we immediately see that

$$
\begin{aligned}
P_{n+p} & =K_{p+1} P_{n}+L_{p+1} P_{n-1}+K_{p} P_{n-2}, \\
P_{2 n} & =K_{n+1} P_{n}+L_{n+1} P_{n-1}+K_{n} P_{n-2} \\
& =K_{n+1} P_{n}+\left(K_{n}+K_{n-1}\right) P_{n-1}+K_{n} P_{n-2}, \\
P_{2 n-1} & =K_{n} P_{n}+\left(K_{n-1}+K_{n-2}\right) P_{n-1}+K_{n-1} P_{n-2} .
\end{aligned}
$$

Now setting $P_{0}=0, \quad P_{1}=P_{2}=1$, we have (10), (11), (12) as special cases of (17), (18), and (19), respectively.

Since 


$$
\left[\begin{array}{c}
P_{n+p} \\
P_{n+p-1} \\
P_{n+p-2}
\end{array}\right]=\left[\begin{array}{ccc}
K_{p+r+1} & L_{p+r+1} & K_{p+r} \\
K_{p+r} & L_{p+r} & K_{p+r-1} \\
K_{p+r-1} & L_{p+r-1} & K_{p+r-2}
\end{array}\right]\left[\begin{array}{l}
P_{n-r} \\
P_{n-r-1} \\
P_{n-r-2}
\end{array}\right],
$$

we also have

$$
P_{n+p}=K_{p+r+1} P_{n-r}+L_{p+r+1} P_{n-r-1}+K_{p+r} P_{n-r-2}
$$

for $\mathrm{n}, \mathrm{p}, \mathrm{r}$ positive integers, $\mathrm{r} \leq \mathrm{n}-2$.

Similarly for $\mathrm{n}, \mathrm{h}, \mathrm{k}$ positive integers, we can show that

$$
P_{n+h+k}=K_{h+k+1} P_{n}+L_{h+k+1} P_{n-1}+K_{n+k} P_{n-1} \text { 。 }
$$

Using (20) and (21), we have the following useful expression:

(22)

$$
\left[\begin{array}{l}
P_{n+h+k} \\
P_{n+h} \\
P_{n}
\end{array}\right]=\left[\begin{array}{ccc}
K_{h+k+1} & L_{h+k+1} & K_{h+k} \\
K_{h+1} & L_{h+1} & K_{h} \\
1 & 0 & 0
\end{array}\right]\left[\begin{array}{ccc}
1 & 1 & 1 \\
1 & 0 & 0 \\
0 & 1 & 0
\end{array}\right]^{n-2}\left[\begin{array}{l}
P_{2} \\
P_{1} \\
P_{0}
\end{array}\right]
$$

It can be shown quite easily that the sequence

$$
\mathrm{P}_{1}, \mathrm{R}_{2}, \mathrm{P}_{2}, \mathrm{R}_{3}, \mathrm{P}_{3}, \cdots, \mathrm{P}_{\mathrm{n}}, \mathrm{R}_{\mathrm{n}+1}, \cdots
$$

is generated by the matrix

$$
\left[\begin{array}{lll}
1 & 1 & 0 \\
1 & 0 & 1 \\
1 & 0 & 0
\end{array}\right],
$$

that is,

(24)

$$
\left[\begin{array}{l}
P_{n} \\
R_{n} \\
P_{n-1}
\end{array}\right]=\left[\begin{array}{lll}
1 & 1 & 0 \\
1 & 0 & 1 \\
1 & 0 & 0
\end{array}\right]^{n-2}\left[\begin{array}{c}
P_{2} \\
R_{2} \\
P_{1}
\end{array}\right] .
$$


It is an interesting and useful fact that this matrix is the transpose of the generating matrix for $\left\{\mathrm{P}_{\mathrm{n}}\right\}$.

Using (24) in a way analogous to that in which we established (21), we prove that

$$
\begin{aligned}
& P_{n+h+k}=K_{h+k+1} P_{n}+K_{h+k} R_{n}+K_{h+k-1} P_{n-1}, \\
& R_{n+h+k}=L_{h+k+1} P_{n}+L_{h+k} R_{n}+L_{h+k-1} P_{n-1},
\end{aligned}
$$

two relations which are not only interesting in themselves but which also give

$$
\left[\begin{array}{l}
P_{n+h+k} \\
R_{n+h} \\
P_{n}
\end{array}\right]=\left[\begin{array}{ccc}
K_{h+k+1} & K_{h+k} K_{h+k-1} \\
L_{h+1} & L_{h} & L_{h-1} \\
1 & 0 & 0
\end{array}\right]\left[\begin{array}{ccc}
1 & 1 & 0 \\
1 & 0 & 1 \\
1 & 0 & 0
\end{array}\right]^{n-2}\left[\begin{array}{l}
P_{2} \\
R_{2} \\
P_{1}
\end{array}\right]
$$

In order to define $\mathrm{P}_{\mathrm{n}}$ for negative $\mathrm{n}$, we use (14) for $\mathrm{n}>0$ written in the form

$$
\left[\begin{array}{c}
P_{n} \\
P_{n+1} \\
P_{n+2}
\end{array}\right]=\left[\begin{array}{lll}
0 & 1 & 0 \\
0 & 0 & 1 \\
1 & 1 & 1
\end{array}\right]^{n}\left[\begin{array}{c}
P_{0} \\
P_{1} \\
P_{2}
\end{array}\right]
$$

Replacing $\mathrm{n}$ by $-\mathrm{n}$ in (28), we have for $\mathrm{n}>0$,

$$
\left[\begin{array}{l}
P_{-n} \\
P_{-n+1} \\
P_{-n+2}
\end{array}\right]=\left[\begin{array}{lll}
0 & 1 & 0 \\
0 & 0 & 1 \\
1 & 1 & 1
\end{array}\right]^{-n}\left[\begin{array}{l}
P_{0} \\
P_{1} \\
P_{2}
\end{array}\right]=\left[\begin{array}{rrr}
-1 & -1 & 1 \\
1 & 0 & 0 \\
0 & 1 & 0
\end{array}\right]^{n}\left[\begin{array}{l}
P_{0} \\
P_{1} \\
P_{2}
\end{array}\right],
$$

which together with (14) determines $P_{n}$ for all $n$ since $P_{0}, P_{1}, P_{2}$ are given. The same result is obtained upon replacing $n$ by $-n$ in (3) to get

$$
\mathrm{P}_{-\mathrm{n}}=\mathrm{P}_{-\mathrm{n}+3}-\mathrm{P}_{-\mathrm{n}+2}-\mathrm{P}_{-\mathrm{n}+1}, \quad \mathrm{n}>0
$$


$\mathrm{R}_{\mathrm{n}}$ is also defined for negative $\mathrm{n}$ by (29) and (30) since

$$
R_{n}=P_{n-1}+P_{n-2} \cdot
$$

This allows us to remove the restriction placed on $n, p, r, h, k$ above.

\section{LINEAR SUMS}

A large number of what we shall call linear sum relations on terms of the sequences $\left\{R_{n}\right\}$ and $\left\{P_{n}\right\}$ were found and proved. Since an exhaustive list is not our aim, only a few of the more interesting ones are listed. No proofs will be given here since the proofs may all be made rather easily by finite induction.

$$
\sum_{i=0}^{n} P_{i}=\frac{1}{2}\left(P_{n+2}+P_{n}+P_{0}-P_{2}\right)
$$

$$
\sum_{i=1}^{n} P_{3 i}=\sum_{i=0}^{3 n-1} P_{i}+P_{0}
$$

$$
\sum_{i=1}^{n} R_{3 i}=P_{3 n}-P_{0}
$$

$$
\sum_{i=1}^{n} R_{3 i+1}=P_{3 n+1}-P_{1}
$$

These relations obviously have special cases for the sequences $K_{n}$ and $L_{n}$. For example (33) becomes

$$
\sum_{i=1}^{n} L_{3 i}=K_{3 n}
$$




\section{QUADRATIC AND CUBIC RELATIONS}

An attempt to parallel the quadratic relations of the Fibonacci sequence failed. A different approach was necessary and this was found in the use of the vector-matrix representation of $P_{n}$. We have the following interesting quadratic form:

$$
\mathrm{P}_{\mathrm{n}}^{2}+\mathrm{P}_{\mathrm{n}-1}^{2}+2 \mathrm{P}_{\mathrm{n}-1} \mathrm{P}_{\mathrm{n}-2}=\mathrm{P}_{2} \mathrm{P}_{2 \mathrm{n}-2}+\mathrm{R}_{2} \mathrm{P}_{2 \mathrm{n}-3}+\mathrm{P}_{1} \mathrm{P}_{2 \mathrm{n}-4}
$$

The proof of (35) follows by considering the left side of the relation as the scalar product of the vectors $\left[\begin{array}{lll}P_{n}, & R_{n}, & P_{n-1}\end{array}\right]$ and $\left[\begin{array}{lll}P_{n}, & P_{n-1}, & P_{n-2}\end{array}\right]$ (recall $\mathrm{R}_{\mathrm{n}}=\mathrm{P}_{\mathrm{n}-1}+\mathrm{P}_{\mathrm{n}-2}$ ), and then using (14) and (24), we have

$$
\begin{gathered}
P_{n}^{2}+P_{n-1}^{2}+2 P_{n-1} P_{n-2}=\left[\begin{array}{lll}
P_{n}, & R_{n}, & P_{n-1}
\end{array}\right]\left[\begin{array}{l}
P_{n} \\
P_{n-1} \\
P_{n-2}
\end{array}\right] \\
=\left[\begin{array}{lll}
P_{2}, & R_{2}, & P_{1}
\end{array}\right]\left[\begin{array}{lll}
1 & 1 & 1 \\
1 & 0 & 0 \\
0 & 1 & 0
\end{array}\right]^{2 n-4}\left[\begin{array}{l}
P_{2} \\
P_{1} \\
P_{0}
\end{array}\right]=\left[\begin{array}{ll}
P_{2}, R_{2}, P_{1}
\end{array}\right]\left[\begin{array}{l}
P_{2 n-2} \\
P_{2 n-3} \\
P_{2 n-4}
\end{array}\right] \\
=P_{2} P_{2 n-2}+R_{2} P_{2 n-3}+P_{1} P_{2 n-4} \\
\text { For } P_{0}=0, \quad P_{1}=P_{2}=1, \quad(35) \text { becomes } \\
K_{n}^{2}+K_{n-1}^{2}+2 K_{n-1} K_{n-2}=K_{2 n-1},
\end{gathered}
$$

which is (12). It was shown that (12) is also a special case of (19), but (35) is not obtainable from (19) nor vice versa.

One of the most interesting relations involving terms of the Fibonacci sequence is the one

$$
\mathrm{C}_{\mathrm{n}-1} \mathrm{C}_{\mathrm{n}+1}-\mathrm{C}_{\mathrm{n}}^{2}=(-1)^{\mathrm{n}}
$$


There is a relation of this nature for the sequence $\left\{P_{n}\right\}$; however as may have been suspected, it has a cubic rather than a quadratic form. The desired relation is

$$
\begin{gathered}
P_{n}^{2} P_{n-3}+P_{n-1}^{3}+P_{n-2}^{2} P_{n+1}-P_{n+1} P_{n-1} P_{n-3}-2 P_{n} P_{n-1} P_{n-2}=P_{0}^{3}+2 P_{1}^{3} \\
+P_{2}^{3}+2 P_{0}^{2} P_{1}+2 P_{0} P_{1}^{2}+P_{0}^{2} P_{2}-2 P_{1} P_{2}^{2}-2 P_{0} P_{1} P_{2}-P_{0} P_{2}^{2}
\end{gathered}
$$

Before proving (36), we note that for $\mathrm{P}_{0}=0, \mathrm{P}_{1}=\mathrm{P}_{2}=1$, (36) becomes

$$
K_{n}^{2} K_{n-3}+K_{n-1}^{3}+K_{n-2}^{2} K_{n+1}-K_{n+1} K_{n-1} K_{n-3}-2 K_{n} K_{n-1} K_{n-2}=1
$$

The proof of (37) follows from (9) and (15) by the use of determinants since

$$
\begin{aligned}
& \mathrm{K}_{\mathrm{n}}^{2} \mathrm{~K}_{\mathrm{n}-3}+\mathrm{K}_{\mathrm{n}-1}^{3}+\mathrm{K}_{\mathrm{n}-2}^{2} \mathrm{~K}_{\mathrm{n}+1}-\mathrm{K}_{\mathrm{n}+1} \mathrm{~K}_{\mathrm{n}-1} \mathrm{~K}_{\mathrm{n}-3}-2 \mathrm{~K}_{\mathrm{n}} \mathrm{K}_{\mathrm{n}-1} \mathrm{~K}_{\mathrm{n}-2}=
\end{aligned}
$$

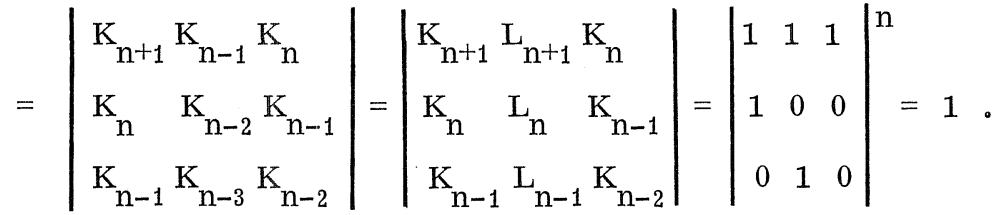

Proof of (36): Even though (36) may be verified in very much the same manner as (37), we adopt a different method of proof since this is more easily used in a generalized version of (36). First, we state the following lemma whose proof the reader can readily supply.

Lemma: Let $\mathrm{A}$ be any $3 \times 3$ matrix and let $\overline{\mathrm{x}}$ and $\overline{\mathrm{y}}$ bethree-dimensional vectors; then the cross product $(A \bar{x}) \times(A \bar{y})$ is equal to the cofactor matrix of A multiplied by $\overline{\mathrm{x}} \mathrm{X} \overline{\mathrm{y}}$; i. e. ,

$$
(A \bar{x}) \quad X \quad(A \bar{y})=(\text { cofactor } A)(\bar{x} \quad x \quad \bar{y}) \text {. }
$$

Now the left side of (36) can be considered as the triple scalar product of the three vectors $\left[P_{n+1}, P_{n}, P_{n-1}\right],\left[P_{n-1}, P_{n-2}, P_{n-3}\right]$, and $\left[P_{n}, P_{n-1}, P_{n-2}\right]$. By (14) and the lemma, 


$$
\begin{aligned}
{\left[\begin{array}{l}
P_{n-1} \\
P_{n-2} \\
P_{n-3}
\end{array}\right] \times\left[\begin{array}{l}
P_{n} \\
P_{n-1} \\
P_{n-2}
\end{array}\right]=\left[\begin{array}{lll}
1 & 1 & 1 \\
1 & 0 & 0 \\
0 & 1 & 0
\end{array}\right]^{n-3}\left[\begin{array}{l}
P_{2} \\
P_{1} \\
P_{0}
\end{array}\right] X\left[\begin{array}{lll}
1 & 1 & 1 \\
1 & 0 & 0 \\
0 & 1 & 0
\end{array}\right]^{n-3}\left[\begin{array}{l}
P_{3} \\
P_{2} \\
P_{1}
\end{array}\right] } \\
=\left[\begin{array}{lll}
0 & 0 & 1 \\
1 & 0 & -1 \\
0 & 1 & -1
\end{array}\right]^{n-3}\left[\begin{array}{ll}
P_{1}^{2} & -P_{2} P_{0} \\
P_{3} P_{0} & -P_{1} P_{2} \\
P_{2}^{2} & -P_{3} P_{1}
\end{array}\right]
\end{aligned}
$$

Therefore

$$
\begin{aligned}
P_{n}^{2} P_{n-3}+P_{n-1}^{3}+ & P_{n-2}^{2} P_{n+1}-P_{n+1} P_{n-1} P_{n-3}-2 P_{n} P_{n-1} P_{n-2} \\
& =\left[\begin{array}{l}
P_{n+1} \\
P_{n} \\
P_{n-1}
\end{array}\right]\left[\begin{array}{c}
P_{n-1} \\
P_{n-2} \\
P_{n-3}
\end{array}\right] \times\left[\begin{array}{c}
P_{n} \\
P_{n-1} \\
P_{n-2}
\end{array}\right] \\
& =\left[\begin{array}{lll}
P_{4}, & P_{3}, & P_{2}
\end{array}\right]\left[\begin{array}{lll}
1 & 1 & 0 \\
1 & 0 & 1 \\
1 & 0 & 0
\end{array}\right]^{n-3}\left[\begin{array}{lll}
0 & 0 & 1 \\
0 & 0 & -1 \\
0 & 1 & -1
\end{array}\right]^{n-3}\left[\begin{array}{l}
P_{1}^{2}-P_{2} P_{0} \\
P_{3} P_{0}-P_{1} P_{2} \\
P_{2}^{2}-P_{3} P_{1}
\end{array}\right] \\
& =P_{4}\left(P_{1}^{2}-P_{2} P_{0}\right)+P_{3}\left(P_{3} P_{0}-P_{2} P_{1}\right)+P_{2}\left(P_{2}^{2}-P_{3} P_{1}\right),
\end{aligned}
$$

which reduces to the right side of (36).

Example: Suppose we let $\mathrm{P}_{0}=0, \mathrm{P}_{1}=1$; then the right side of (36) becomes

$$
\mathrm{P}_{2}^{3}-2 \mathrm{P}_{2}+2
$$

Setting this expression equal to zero and solving for $\mathrm{P}_{2}$, we see that there exist algebraic integers, say $\overline{\mathrm{P}}_{0}, \overline{\mathrm{P}}_{1}, \overline{\mathrm{P}}_{2}$, such that for the sequence $\left\{\overline{\mathrm{P}}_{\mathrm{n}}\right\}$,

$$
\overline{\mathrm{P}}_{\mathrm{n}}^{2} \overline{\mathrm{P}}_{\mathrm{n}-3}+\overline{\mathrm{P}}_{\mathrm{n}-1}^{3}+\overline{\mathrm{P}}_{\mathrm{n}-2}^{2} \overline{\mathrm{P}}_{\mathrm{n}+1}=\overline{\mathrm{P}}_{\mathrm{n}+1} \overline{\mathrm{P}}_{\mathrm{n}-1} \overline{\mathrm{P}}_{\mathrm{n}-3}+2 \overline{\mathrm{P}}_{\mathrm{n}} \overline{\mathrm{P}}_{\mathrm{n}-1} \overline{\mathrm{P}}_{\mathrm{n}-2} \text {. }
$$


The lemma and (22) may be used as in the previous method of proof to show that for $h, k, n, m, t$ integers

$$
\begin{aligned}
& P_{n+h} P_{n+m} P_{n+h+k+t}+P_{n} P_{n+h+t} P_{n+h+k+m}+P_{n+t} P_{n+h+k} P_{n+h+m} \\
& -P_{n} P_{n+h+m} P_{n+h+k+t}-P_{n+m} P_{n+h+k} P_{n+h+t}-P_{n+h} P_{n+t} P_{n+h+k+m}
\end{aligned}
$$$$
=\left(K_{h} L_{h+k+1}-K_{h+k} L_{h+1}\right)\left[P_{t+2}\left(P_{1} P_{m}-P_{0} P_{m+1}\right)+P_{t+1}\left(P_{0} P_{m+2}-P_{2} P_{m}\right)\right.
$$$$
\left.+\mathrm{P}_{\mathrm{t}}\left(\mathrm{P}_{2} \mathrm{P}_{\mathrm{m+1}}-\mathrm{P}_{1} \mathrm{P}_{\mathrm{m}+2}\right)\right]
$$

There are many interesting special cases of this relation. We mention a few. If $\mathrm{P}_{0}=0, \mathrm{P}_{1}=\mathrm{P}_{2}=1$, (38) becomes

$$
\begin{gathered}
K_{n+h} K_{n+m} K_{n+h+k+t}+K_{n} K_{n+h+t} K_{n+h+k+m}+K_{n+t} K_{n+h+k} K_{n+h+m} \\
\quad-K_{n} K_{n+h+m} K_{n+h+k+t}-K_{n+m} K_{n+h+k} K_{n+h+t} \\
\quad-K_{n+h} K_{n+t} K_{n+h+k+m} \\
=\left(K_{h} K_{h+k-1}-K_{h+k} K_{h-1}\right)\left(K_{t-1} K_{m}-K_{t} K_{m-1}\right) \cdot \\
\text { If } k_{h}=t, \quad m=1, \quad(39) b e c o m e s \\
K_{n+1} K_{n+h} K_{n+3 h}+K_{n} K_{n+2 h} K_{n+2 h+1}+K_{n+h} K_{n+h+1} K_{n+2 h}-K_{n} K_{n+h+1} K_{n+3 h} \\
\quad-K_{n+1} K_{n+2 h}^{2}-K_{n+h}^{2} K_{n+2 h+1}=K_{h-1} K_{h} K_{2 h-1}-K_{h-1}^{2} K_{2 h} ;
\end{gathered}
$$

and if $\mathrm{t}=\mathrm{h}, \mathrm{k}=\mathrm{m}-\mathrm{h}$, (39) reduces to

$$
\begin{aligned}
K_{n} K_{n+2 h} K_{n+2 m}+2 K_{n+h} K_{n+m} K_{n+h+m} & -K_{n} K_{n+h+m}^{2}-K_{n+m}^{2} K_{n+2 h} \\
& -K_{n+h}^{2} K_{n+2 m}=-\left(K_{h} K_{m-1}-K_{m} K_{n-1}\right)^{2}
\end{aligned}
$$

In order that the above results be valid, we must choose $\mathrm{h}$ and $\mathrm{k}$ so that

$$
\mathrm{K}_{\mathrm{n}} \mathrm{K}_{\mathrm{n}+\mathrm{k}-1}-\mathrm{K}_{\mathrm{h}+\mathrm{k}} \mathrm{K}_{\mathrm{h}-1}=\mathrm{K}_{\mathrm{h}} \mathrm{L}_{\mathrm{h}+\mathrm{k}+1}-\mathrm{K}_{\mathrm{h}+\mathrm{k}} \mathrm{L}_{\mathrm{h}+1} \neq 0
$$


for in the proof of $(38)$, we assume that the matrix

$$
\left[\begin{array}{ccc}
\mathrm{K}_{\mathrm{h}+\mathrm{k}+1} & \mathrm{~L}_{\mathrm{h}+\mathrm{k}+1} & \mathrm{~K}_{\mathrm{h}+\mathrm{k}} \\
\mathrm{K}_{\mathrm{h}+1} & \mathrm{~L}_{\mathrm{h}+1} & \mathrm{~K}_{\mathrm{h}} \\
1 & 0 & 0
\end{array}\right]
$$

is non-singular.

Using (27) we can find relationships involving terms of both the sequences $\left\{R_{n}\right\}$ and $\left\{P_{n}\right\}$ which reduce to an expression independent of $n_{\circ}$ For example, it may be proved that

$$
\begin{aligned}
& \text { (42) } P_{n+h+k+t}\left(R_{n+h} P_{n+m}-P_{n} P_{n+h+m}\right)+R_{n+h+t}\left(P_{n} P_{n+h+k+m}-P_{n+m} P_{n+h+k}\right) \\
& +P_{n+t}\left(P_{n+h+k} R_{n+h+m}-R_{n+h} P_{n+h+k+m}\right)=\left(K_{h+k-1} L_{h}-K_{n+k} L_{h-1}\right) \\
& {\left[P_{t+2}\left(P_{1} P_{m}-P_{0} P_{m+1}\right)+P_{t+1}\left(P_{0} P_{m+2}-P_{2} P_{m}\right)+P_{t}\left(P_{2} P_{m+1}-P_{1} P_{m+2}\right)\right]}
\end{aligned}
$$

It should be noted that no terms of the sequence $\left\{R_{n}\right\}$ appear on the right side of (42) and also that the second factor on the right side of the equality sign in (42) is the same as the second factor on the right side of (38).

\section{MISCELLANEOUS RESULTS}

We conclude with some miscellaneous results. The following limiting relations may be established using (13) and the fact that $r_{1}, r_{2}$, the two complex roots of

$$
x^{3}-x^{2}-x-1=0,
$$

are such that

$$
\begin{gathered}
\left|\mathrm{r}_{1}\right|=\left|\mathrm{r}_{2}\right|<1 . \\
\operatorname{limit}_{\mathrm{n} \rightarrow \infty} \frac{\mathrm{P}_{\mathrm{n}+1}}{\mathrm{P}_{\mathrm{n}}}=\frac{1-\sqrt[3]{3 \sqrt{33}-19}+\sqrt[3]{19+3 \sqrt{33}}}{3}, \\
\operatorname{limit}_{\mathrm{n} \rightarrow \infty} \frac{\mathrm{P}_{\mathrm{n}+\mathrm{h}}}{\mathrm{P}_{\mathrm{n}}}=\left(\frac{1-\sqrt[3]{3 \sqrt{33}-19}+\sqrt[3]{19+3 \sqrt{33}}}{3}\right) \mathrm{h}
\end{gathered}
$$


By induction the following theorem may be established:

Theorem: For every positive $n$,

$$
\begin{aligned}
\mathrm{K}_{4 \mathrm{n}} & \equiv \mathrm{K}_{4 \mathrm{n}-1} \equiv 0(\bmod 2) \\
\mathrm{K}_{4 \mathrm{n}-2} & \equiv \mathrm{K}_{4 \mathrm{n}-3} \equiv 1(\bmod 2) \\
\mathrm{K}_{4 \mathrm{n}} & \equiv 0 \quad,
\end{aligned}
$$

If we let $\mathrm{D}\left(\mathrm{P}_{0}, \mathrm{P}_{1}, \mathrm{P}_{2}, \cdots, \mathrm{P}_{\mathrm{n}}\right)$ be the determinant

$$
\left|\begin{array}{ccccc}
\mathrm{P}_{0} & \mathrm{P}_{1} & \mathrm{P}_{2} & \cdots & \mathrm{P}_{\mathrm{n}} \\
\mathrm{P}_{1} \mathrm{P}_{2} & \mathrm{P}_{3} & \cdots & \mathrm{P}_{\mathrm{n}+1} \\
\cdot & \cdot & \cdots & \cdot \\
\mathrm{P}_{n} \mathrm{P}_{n+1} & \mathrm{P}_{n+2} & \cdots & \mathrm{P}_{2 \mathrm{n}}
\end{array}\right|
$$

it can be shown that for $\mathrm{n} \geq 3$,

$$
\mathrm{D}\left(\mathrm{P}_{0}, \mathrm{P}_{1}, \mathrm{P}_{2}, \cdots, \mathrm{P}_{\mathrm{n}}\right)=0
$$

This material is taken from Some Generalizations and Extensions of the Fibonacci Sequence, a thesis submitted to the University of Pittsburgh by the first author in partial fulfillment of requirements for the $\mathrm{Ph}_{\mathrm{o}} \mathrm{D}$. degree.

\section{REFERENCE}

1. M. Agronomoff, "Une série récurrente," Mathesis, ser.4, vol. 4 (1914), p. 126 . 